\title{
Antibacterial and Phytochemical Screening of Ziziphus Jujuba (Jujube/Magarya) Leaf Extract in Kaduna Metropolis
}

\author{
S. B. Sanusi*, A. Usman, S. M. Lawal, F. M. Musa, H. M. Auwal \\ Department of Microbiology, \\ Faculty of Science, \\ Kaduna State University, \\ Tafawa Balewa Way, \\ PMB 2339, Kaduna, Nigeria
}

Email: sanusishuaibu@gmail.com

\begin{abstract}
Ziziphus jujuba from the family of Rhamnaceae is widely distributed in both tropical and subtropical countries. Different parts of the plant have been used traditionally for several biological purposes including fungal and antibacterial and antidiarrheal. This study was aimed to assess the antibacterial activity of Ziziphus jujuba leaf extract against bacteria isolated from vaginal swab. Preliminary phytochemical screening of the leaves extract of Ziziphus jujuba was carried out using standard analytical methods. The aqueous and ethanol extracts of Ziziphus jujuba leaf were screened for antimicrobial activities against Staphylococcus aureus and Escherichia coli isolated from vaginal swabs using agar well diffusion and broth dilution assay. The results of the phytochemical constituents revealed the presence of alkaloids, steroids, tannins, phenols, cardiac glycosides, and terpenes in the ethanol extract while alkaloids, steroids, tannins, cardiac glycosides, phenols, and saponins were present in the aqueous extract. The inhibitory zones of the ethanol extract against $S$. aureus ranged between $13.00-15.00 \mathrm{~mm}$ while that of E. coli ranged between $7.00-10.00 \mathrm{~mm}$ at 50 and $100(\mathrm{mg} / \mathrm{ml})$ respectively. The inhibitory zone of the aqueous extract against the clinical isolates of S. aureus ranged from 9.00- 11.00 and 6.00-8.00 (mm) for E. coli at 50 and $100(\mathrm{mg} / \mathrm{ml})$ respectively. However, S. aureus was more susceptible to the extract with an MIC of $100 \mathrm{mg} / \mathrm{ml}$. The observed inhibitory activities of the leaf extract against the clinical isolates could be due to phytochemical constituents present in the plant extracts of Ziziphus jujuba.
\end{abstract}

Keywords: Antibacterial evaluation, Escherichia coli, In vitro, Phytochemicals, Staphylococcus aureus, Ziziphus jujuba,

\section{INTRODUCTION}

Bacterial vaginosis has received little attention since it is considered to be a trivial infection, Though, it is a morbid disease in terms of loss of working hours and cost of treatment (Donders et al., 2002). Moreover, it increases the threat to acquiring human immunodeficiency virus (HIV) (Myer et al., 2005) and other sexually transmitted diseases (STDs) including gonorrhea, herpes simplex virus type 2 (HSV-2) and trichomoniasis (Cherpes et al., 2003). In addition, it increases the risk of miscarriage, preterm labor, preterm delivery, and postpartum complications such as endometritis and wound infections in pregnant women (CDC. 2006; Bittew et al., 2017). The existing studies on antimicrobial profile proved that, nosocomial-causing bacteria as well as other infectious bacteria become 
highly resistant to different antibiotic groups. Hence, this situation becomes a clinical threat to human beings (Leopold et al., 2014).

Ethnobotanical knowledge has always guided the search for new medications from medicinal plants. Though, this practice of using medicinal plants as herbal therapies to prevent and cure several diseases differs from one community to another (Kubmarawa et al., 2008). Natural extracts have significant effects and it alternative therapeutic properties due to some bioactive compound they contained enhances effectiveness of diseases treatment (Ogbeba et al., 2017).

Jujube (Ziziphus jujuba Mill.) from the family of Rhamnaceae (Chen et al., 2015a) has since gained attention in different fields ranging from nutritional and food sciences credit to its medicinal and nutritional properties (Wang et al., 2016). The fruits of jujube are consumed freshly, though, can also be processed into products, including alcoholic beverage, jam, cake, candied snack, bread and sweetened tea syrup (Zozio et al., 2014; Wojdyło et al., 2016a). Further, the fruits of jujube also contain high level of mineral, organic acids, protein, polyphenols and vitamins (Park et al., 2012; Gao \& Wang, 2013). These constituents play a significant role in affecting the nutritional properties of jujube. Jujube fruits for example, content phenolic compounds that possess anti-cancer, anti-obesity, antioxidative and antidiabetes properties (Yu et al., 2012; Wojdyło et al., 2016b). Ganachari et al. (2004) reported that saponin, alkaloids, polysaccharides, steroids, glycosides and terpenoids were detected in the extracts of Z. jujube.

The in vivo anxiolytic effect had previously been reported in a poly-herbal substance that consists of Z. jujube seed extract (Mesaik et al., 2018). Inhibitory assay performed by ethanolic extract of $Z$. jujuba root on fungi Candida albicans, A. niger, Aspergillus flavus and $C$. tropicalis showed remarkable antifungal activity (Yuan et al., 2017). Also, the root bark extract of $Z$. jujuba exhibited inhibitory activity against 20 bacteria isolates (Beg et al., 2016).

A traditional Chinese preparation (Huangqin Tang) with fruit content from $Z$. jujuba displayed remarkable antispasmodic and anti-inflammatory effect (Triantafillidis et al., 2016). In Nigeria, the leaves of Z. jujuba is used traditionally by women after period to wash their private parts and also to cure toilet infections. The aim of the study is to evaluate the antibacterial activities of $Z$. jujuba leaves extract against bacteria isolated from vaginal swab.

\section{MATERIALS AND METHODS}

\section{Collection of samples}

Leaves of Z. jujuba were obtained from Kaduna metropolitan area and then conveyed to Biological Science Department, Kaduna State University (KASU) in sterile polythene bags for authentication. Voucher number of V/No: 5332 was assigned to the plant. The leaves were then washed and air dried for 10 days. The dried leaves were ground to powdered form using mortar and pestle. The powder was then placed in clean black polythene bags, labelled and kept until required.

The bacterial isolates including Escherichia coli and Staphylococcus aureus were collected from Medical Microbiology Laboratory of 44 Nigerian Army Hospital Kaduna, Kaduna State. The Isolates were transferred to the laboratory in ice box and maintained at $4^{\circ} \mathrm{C}$ in the refrigerator until needed. 


\section{Laboratory procedures}

The aqueous extract of $Z$. jujuba leaf was prepared using distilled water following the methods of Ogbeba et al. (2017). 100g of Z. jujuba leaves were dissolved in $500 \mathrm{ml}$ of distilled water. The solution was kept for 3 days at room temperature. The solution was filtered using a Whattman (no.1) filter paper in a sterile test tube. The filtrate was then concentrated by evaporation at $50^{\circ} \mathrm{C}$ using water bath. The concentrated extract was kept in a screw cap bottle at $4^{\circ} \mathrm{C}$. The ethanol extract of dried Z. jujuba leaves was also prepared via the same procedure as that of aqueous extract.

\section{Phytochemical Screening}

The phytochemical qualitative screening of Z. jujuba leaves extract was carried out according to Ogbeba et al. (2017) to determine the presence phytoconstituents such as flavonoids, alkaloids, tannins, glycosides, plabotannins, terpenes, cardiac glycosides, saponins, steroids and terpenoids.

\section{Standardization of Clinical Isolates}

The method of Oyeleke and Manga (2008) was used to standardize the organisms. The isolates being tested were cultured on Mueller Hilton Agar (MHA) at $37^{\circ} \mathrm{C}$ overnight. Colonies formed were inoculated into a tube containing Mueller Hinton broth until the turbidity is equal to that of $0.5 \mathrm{McF}$ arland standards.

\section{Preparation of Extract Concentration}

One gram of the crude extract was dissolved in $10 \mathrm{ml}$ of $2 \%$ Dimethyl Sulfoxide (DMSO) in a test tube to get $100 \mathrm{mg} / \mathrm{ml}$ which the highest stock concentration used. This was followed by serial dilution with distilled water to give various concentrations $(50 \mathrm{mg} / \mathrm{ml}, 25 \mathrm{mg} / \mathrm{ml}$ and $12.5 \mathrm{mg} / \mathrm{ml}$ ). Aqueous dilution was also made using the same technique.

\section{Antibacterial Susceptibility Test of Z. jujuba}

Agar well diffusion method of Olutiola et al. (2016) was used to determine the inhibitory activity of aqueous and ethanolic extracts of $Z$. jujube against the bacterial isolates. The susceptibility test was carried out using $100 \mathrm{mg} / \mathrm{ml}, 50 \mathrm{mg} / \mathrm{ml}, 25 \mathrm{mg} / \mathrm{ml}$, and $12.5 \mathrm{mg} / \mathrm{ml}$ concentrations. The standardized isolates were spread $(0.1 \mathrm{ml})$ throughout the surface of MHA plate. $6 \mathrm{~mm}$ diameter wells were made on the agar using a sterile cork borer. $0.1 \mathrm{ml}$ of the leaf extract at the labelled concentration $(100 \mathrm{mg} / \mathrm{ml}, 50 \mathrm{mg} / \mathrm{ml}, 25 \mathrm{mg} / \mathrm{ml}$, and $12.5 \mathrm{mg} / \mathrm{ml}$ ) was dropped separately in each well using a micropipette. It was then allowed to stand for 4-5 hours for proper diffusion of the extract. Incubation (without inverting the plates) was done for $18-24$ hours at $37{ }^{\circ} \mathrm{C}$. About $0.1 \mathrm{ml}$ of $2 \%$ DMSO and ciprofloxacin served as both the negative and positive control respectively. The presence of zone of inhibition around the wells indicated bacterial inhibition by the extracts while the absence of zone indicated no inhibition. The diameter of inhibition zone was then measured using a well calibrated meter ruler.

\section{Determination of Minimum Inhibitory Concentration (MIC)}

The method of Doughari et al. (2017) was used to determined the MIC of the extract. Concentrations $(100 \mathrm{mg} / \mathrm{ml}$ and $50 \mathrm{mg} / \mathrm{ml})$ of the extracts were prepared and $1 \mathrm{ml}$ each of the varying concentrations was dispensed into test tubes according to the concentration using sterile pipette. About $2 \mathrm{ml}$ of sterile Mueller Hilton broth was dispensed into the test tubes. Loopful of the standardized organisms was inoculated into the varying extracts. Inoculum control was prepared by inoculating $1 \mathrm{ml}$ of Mueller Hilton Broth (MHB) with the standardized inoculum in a test tube. Broth control was prepared by inoculating $2 \mathrm{ml}$ of 
MHB in a test tube and extract control was prepared by inoculating $1 \mathrm{ml}$ of the crude extract with $1 \mathrm{ml}$ of the MHB in a test tube. All the tubes were incubated overnight at $37^{\circ} \mathrm{C}$. The turbidity was compared with the controls and the tubes with the minimum concentration showing no growth was taken as the MIC.

\section{RESULTS}

The outcome of the phytochemical screening of ethanol and aqueous extracts of Z. jujuba is presented in Table 1. Phytochemicals such as terpenes, tannins, alkaloids, phenols, steroids and cardiac glycosides were present in the ethanol. The phytochemicals including phenols, tannins, saponins, steroids, alkaloids and cardiac glycosides were present in the aqueous extract.

Table 1: Phytochemical Screening of Z. jujuba ethanol and aqueous Extracts.

\begin{tabular}{lcc}
\hline Active Components & Ethanol Extract & Aqueous Extract \\
\hline Phenols & + & + \\
Terpenes & + & + \\
Steroids & + & + \\
Cardiac Glycosides & - & - \\
Quinones & - & - \\
Plabotannins & - & + \\
Saponins & - & - \\
Glycosides & + & + \\
Alkaloids & + & + \\
Tannins & - & -
\end{tabular}

$+=$ Positive $\quad$ - = Negative

The zone of inhibition of Z. jujuba ethanol extract is presented in Table 2. The zone of inhibition against $S$. aureus ranged between 13.00-15.00 ( $\mathrm{mm})$ at varied concentration $(\mathrm{mg} / \mathrm{ml})$ of $100,50,25$, and 12.5. Similarly, the zone of inhibition of Z. jujuba against E. coli ranged between $7.00-10.00(\mathrm{~mm})$ at varied concentration $(\mathrm{mg} / \mathrm{ml})$ of $100,50,25$, and 12.5 . More inhibitory effect of the leaf extract was observed on $S$. aureus.

Table 2: Inhibitory Activity of Ethanolic Leaf Extract of Ziziphus jujuba against the Bacterial Isolates

\begin{tabular}{llllll}
\hline Organism & $100 \mathrm{mg} / \mathrm{ml}$ & $50 \mathrm{mg} / \mathrm{ml}$ & $25 \mathrm{mg} / \mathrm{ml}$ & $12.5 \mathrm{mg} / \mathrm{ml}$ & Control \\
\hline S. aureus & 15.00 & 13.00 & - & - & 40.00 \\
E. coli & 10.00 & 7.00 & - & - & 23.00 \\
\hline
\end{tabular}

The zone of inhibition of Z. jujuba aqueous leaf extract is presented in Table 3. The zone of inhibition against $S$. aureus ranged between $9.00-12.00(\mathrm{~mm})$ at varied concentration $(\mathrm{mg} / \mathrm{ml})$ of $100,50,25$, and 12.5. Similarly, the zone of inhibition of Z. jujuba against E. coli ranged between $6.00-8.00(\mathrm{~mm})$ at varied concentration $(\mathrm{mg} / \mathrm{ml})$ of $100,50,25$, and 12.5 . More inhibitory effect of the leaf extract was observed against $S$. aureus. 
Table 3: Inhibitory Activity of Aqueous Leaf Extracts of $\quad$ Z. jujuba against the Bacterial Isolates

\begin{tabular}{llllll}
\hline Organisms & $100 \mathrm{mg} / \mathrm{ml}$ & $50 \mathrm{mg} / \mathrm{ml}$ & $25 \mathrm{mg} / \mathrm{ml}$ & $12.5 \mathrm{mg} / \mathrm{ml}$ & Control \\
\hline S. aureus & 11.00 & 9.00 & - & - & 40.00 \\
E. coli & 8.00 & 6.00 & - & - & 23.00 \\
\hline
\end{tabular}

The result of MIC is presented in Table 4. The highest MIC of the leaf extract of Z. jujuba against $S$. aureus was observed to be $100 \mathrm{mg} / \mathrm{ml}$ in both aqueous and ethanol extracts. E. coli showed no activity in the MIC as turbidity appears at all concentrations. As for the minimum bactericidal concentration, the result indicated presence of growth.

Table 4: Minimum Inhibitory Concentration and Minimum Bactericidal Concentration of Leaf Extract against the Bacterial Isolates.

\begin{tabular}{lll}
\hline Organisms & MIC $(\mathbf{m g} / \mathbf{m l})$ & MBC $(\mathbf{m g} / \mathbf{m l})$ \\
\hline S. aureus & 100 & - \\
E. coli & - & -
\end{tabular}

$\mathrm{MIC}=$ Minimum Inhibitory Concentration $\mathrm{MBC}=$ Minimum Bactericidal Concentration

\section{DISCUSSION}

Medicinal plants play very important roles against various diseases such as microbial infections, cancers and other disorders like diabetes. The antimicrobial actions of such plants have been attributed to the presence of certain phytochemical constituents (Ogbeba et al., 2017). Compounds like alkaloids, glycosides, phenols, tannins, sterols and cardiac glycosides were detected from both ethanol and aqueous extracts of Z. jujuba leaf. Similar phytochemicals were detected from same leaf by Elaloui et al. (2014). The detection of sterol in this study is in line with the study conducted by Elaloui et al. (2014) which reported the present of stigmasterol and B-sitosterol in leaf extract of jujube. Sterol proved to be very active against human pathogenic bacteria (Kavita, 2014). Thus, the antibacterial properties of the extract could be as the result of the sterol compound present. Alkaloids contain analgestic, antibacterial and anti-inflammatory properties which were reported by Pareek (2001). Phenol was also isolated from leaf extracts of both ethanol and aqueous from the leaf of Z. jujube (Elaloui et al., 2017).

The Ethanol extract exhibited more antibacterial activities than the aqueous, this could be due to the fact that ethanol is an organic solvent and can extract more phytoconstituents than water. This was also confirmed from the previous study conducted by Medini et al. (2014). The result of susceptibility of bacterial isolates to leaf extracts of Z. jujuba were comparable to ciprofloxacin (positive standard) which highlighted the possibility of using the Z. jujuba leaf as either an alternative or complementary antibacterial agent in order to minimize the issue of bacterial vaginal infection of women who are resistant to the antibiotic The selected bacterial isolates used in this study has showed good susceptibility to aqueous and ethanol extracts of $Z$. jujuba at varied concentrations. This indicated that the activities of the extracts were dose dependent, thus showing concordance with Dubey et al. (2010) and Abd-Alrahman et al. (2013) that reported the relationship between the antimicrobial efficacy of Z. jujuba and Z. mauritiana at varied concentrations. The variation in susceptibility of isolates to varied concentrations may be due to the differences in the cell walls of the bacteria where Staphylococcus aureus being a Gram positive bacteria with no lipopolysaccharides tend to allow diffusion of the active components, whereas E. coli being Gram negative bacteria possess lipopolysaccharides that might have prevented penetration of active components of extracts. The $S$. aureus showed higher susceptibility than E. coli 
which may be attributed to the fact that E. coli is usually resistant to most antibiotics due to permeability barriers afforded by its outer membrane that is composed of lipopolysaccharides. This was also in line with the work of Yahia et al. (2020), where higher zone of inhibition was observed on Gram positive bacteria compared to Gram negative bacteria, but contradicted the work of Abubakar et al. (2018) where Gram negative bacteria (E. coli) showed more susceptibility than Gram positive bacteria (S. aureus) at $150 \mathrm{mg} / \mathrm{ml}$ concentration. However, all activities of the extract were dose dependent which is similar to the research conducted by Sakha et al. (2018) where it was observed that at high concentration, exhibited more antibacterial activity.

The low MIC and MBC exhibited by the plant against the isolates were attributed to effectiveness of the plant extracts. This contradicts the report of Dubey et al. (2010) where MIC and MBC of low concentrations were obtained against E. coli and S. aureus. The differences could be as a result of geographical location where the plants were collected and method of extraction. The results of this work is similar with the previous researches suggesting effective antibacterial activity of Z. jujuba against both Gram positive and Gram negative bacterial isolates (Yahia et al., 2020; Abubakar et al., 2018; Elaloui et al., 2017; Dubey et al., 2010).

\section{CONCLUSION}

In this study, important phytochemical constituents were detected in both ethanol and aqueous leaf extracts of $Z$. jujuba. The extracts exhibited significant antibacterial activities on clinical isolates including $S$. aureus and E. coli at varied concentration. S. aureus was more susceptible to the extracts at MIC of $100 \mathrm{mg} / \mathrm{ml}$. The phytochemicals detected in the plant extracts could be responsible for the observed antibacterial activities. Further research on fractionation should be done on the leaf extract of Z. jujuba due to its high antibacterial activity. The toxicity profile of this plant should be carried out so as to establish its safety/therapeutic index.

\section{REFERENCES}

Abd-AlRahman, S.H., Salem-Bekhit, M.M. and Elhalwagy, M.E.A. (2013). Chemical composition and antimicrobial activity of Ziziphus jujuba seed extracts. Journal of pure and applied microbiology, 7: 379-385.

Abubakar, A. L., Dandare, A., Abubakar, I. H., Yerima, M. and Wasagu, R. S. U. (2018). Antimicrobial activities of Acacia nilotica, Ziziphus jujuba Linn and Lawsonia inermis. Nigerian Journal of Basic and Applied Sciences, 26(2): 1-8.

Beg, M. A., Teotia, U. and Farooq, S. (2016). In vitro antibacterial and anticancer activity of Ziziphus. J. Med. Plants Stud, 4(5): 230-233.

Bitew, A., Abebaw, Y., Bekele, D. and Mihret, A. (2017). Prevalence of bacterial vaginosis and associated risk factors among women complaining of genital tract infection. International Journal of Microbiology, 1(1): 7.

Centers for Disease Control and Prevention. (2006). "Sexually transmitted diseases, treatment guidelines" MMWR, 55(11): 50-54.

Cherpes, L. A., Meyn, M. A., Krohn, J. G., Lurie, T. L. and Hillier, S. L. (2003). “Association between acquisition of herpes simplex virus type 2 in women and bacterial vaginosis," Clinical Infectious Diseases, 37(3): 319-325.

Chen, Q., Bi, J., Wu, X., Yi, J., Zhou, L., and Zhou, Y. (2015a). Drying kinetics and quality attributes of jujube (Zizyphus jujuba, Miller) slices dried by hot-air and short- and 
medium-wave infrared radiation. Lebensmittel-Wissenschaft + Technologie, 64(2): 759766.

Donders, G. G., Vereecken, A., Bosmans, E., Dekeersmaecker,A., Salembier, G., and Spitz, B. (2002) "Definition of a type of abnormal vaginal flora that is distinct from bacterial vaginosis: Aerobic vaginitis," BJOG: An International Journal of Obstetrics and Gynaecology, 109(1): 34-43.

Doughari, J. H., Pukuma, M. S. and De, N. (2017). Antibacterial effects of Balanite aegyptiaca on Salmonella Typhi. African Journal of Biotechnology, 6(19): 2212-2215.

Dubey, R., Dubey, K., Janapati, Y.K., Sridhar, C. and Jayaveera K.N. (2010). Antimicrobial studies of aqueous, methanolic and saponins extract of leaf of Ziziphus mauritiana on human vaginal pathogens causing UTI infections. International Journal of Pharmacy and Life Sciences, 1(2): 77-81.

Elaloui, M., Ennajah, A., Ghazghazi, H., Youssef, I. B., Othman, N. B., Hajlaoui, M. R. and Laamouri, A. (2017). Quantification of total phenols, flavonoids and tannins from Ziziphus jujuba (mill.) and Ziziphus lotus (Desf). Leaf extracts and their effects on antioxidant and antibacterial activities. International Journal of Secondary Metabolite, 4(1), 18-26.

Elaloui, M., Laamouri, A., Fabre, J., Mathieu, C., Vilarem, G. and Hasnaoui, B. (2014). Distribution of free amino acids: polyphenols and sugars of Ziziphus jujuba pulps harvested from plants grown in Tunisia. Nat Prod Res. 29: 94-97.

Gao, Q. H. and Wang, M. (2013). Response to comment on effect of drying of jujubes (Ziziphus jujuba Mill.) on the contents of sugars, organic acids, a-tocopherol, $\beta$ carotene, and phenolic compounds. Journal of Agricultural and Food Chemistry, 61(19), 4665.

Huang, L.Y.W., Cai, B., Li, D., Liu, J. and Liu, M. (1990). A preliminary study on the pharmacology of the compound prescription huangqin tang and its component drugs. Zhongguo Zhong Yao Za Zhi.5: 115-128.

Ganachari, M.S., Shiv, K. and Bhat, K.G. (2004). Effect of Ziziphus jujube leaves extract on phagocytosis by human neutrophils. Journal of Natural Remedies. 41: 47-51

Kubmarawa, D., Khan, M. E., Punah, A. M. and Hassan, M. (2008). Phytochemical screening and antimicrobial efficacy of extracts from Khaya senegalensis against human pathogenic bacteria. African Journal of Biotechnology, 7(24): 4563 - 4566.

Kang, K.B., Ming, G., Kim, G.J., Choi, H., Oh, W.K., and Sung, S.H. (2015). Jubanines F-J, cyclopeptide alkaloids from the roots of Ziziphus jujuba. Phytochemistry 119; 90-95.

Kavita, K., Singh, V.K. and Jha, B. (2014). 24-Branched $\Delta 5$ sterols from Laurencia papillosa red seaweed with antibacterial activity against human pathogenic bacteria. Microbiological research, 169(4): 301-306.

Leopold, S. J., Vanleth. F., Tarekegn. H. and Schultsz, C. (2014). “Antimicrobial drug resistance among clinically relevant bacterial isolates in sub-Saharan Africa: a systematic review," Journal of Antimicrobial Chemotherapy, 69(9): 2337-2353.

Li, Y., Fang, W., Zhu, G., Cao, K., Chen, C., Wang, X., and Wang, L. (2016). Accumulated chilling hours during endodormancy impact blooming and fruit shape development in peach (Prunus persica L.). Journal of Integrative Agriculture, 15(6): 1267-1274.

Medini, F., Fellah, H., Ksouri, R. and Abdelly, C. (2014). Total phenolic, flavonoid and tannin contents and antioxidant andantimicrobial activities of organic extracts of shoots of the plant Limonium delicatulum Extremophile. J Taibah Univ. Sci. 8: 216-224.

Mesaik, A. M., Poh, H. W., Bin, O. Y., Elawad, I. and Alsayed, B. (2018). In vivo antiinflammatory, anti-bacterial and anti-diarrhoeal activity of Ziziphus Jujuba fruit extract. Open access Macedonian journal of medical sciences, 6(5): 757. 
Myer, L. Denny, R., Telerant, M., De Souza, T. C., Wright Jr., and Kuhn, L. (2005). “Bacterial vaginosis and susceptibility to HIV infection in South African women: Anested casecontrol study," Journal of InfectiousDiseases, 192(8): 1372-1380.

Ogbeba, J., Iruolaje, F. O. and Dogo, B. A. (2017). Antimicrobial efficacy of Guiera senegalensis and Prosopis africana leave extract on some bacterial pathogens. European Journal of Biology and Medical Science Research, 5(2): 27-36.

Olutiola, P. O., Famurewa, O. and Sonntag, H. G. (2016). An Introduction to General Microbiology, a Practical Approach. Ikeja: 2nd Bolabay Publications. Pp. 35-65.

Oyeleke, S. B. and Manga, S. B. (2008). Essential of Laboratory Practical in Microbiology. Minaa: Tobest Publishers. Pp. 36-75.

Pareek. O.P. (2001). International Centre for Underutilized Crops, University of Southampton, Southampton, UK. Fruits for the Future 2: 12

Park, H. J., Lee, S. H., Kim, H. Y., Jang, G. Y., Hwang, I. G., Woo, K. S., Kwon, O.-S., Lee, J.S., \& Jeong, H.-S. (2012). Changes in chemical components and antioxidant activity of dried jujube with different aging temperatures and durations. Journal of the Korean Society of Food Science \& Nutrition, 41(5): 591-597.

Sakha, H., Shretha, S., Acharya, S., Dhakal, D., Thapaliya, S. and Prajapati, K. (2018). Antibacterial activity of ethanolic extract of medicinal plants against human pathogenic bacteria. Tribhuvan University Journal of Microbiology, 5: 1.

Triantafillidis, J. K., Triantafyllidi, A., Vagianos, C. and Papalois, A. (2016). Favorable results from the use of herbal and plant products in inflammatory bowel disease: evidence from experimental animal studies. Annals of gastroenterology: quarterly publication of the Hellenic Society of Gastroenterology, 29(3): 268.

Wang, B., Huang, Q., Venkitasamy, C., Chai, H., Gao, H., Cheng, N., Cao, W., Lv, X., and Pan, Z. (2016). Changes in phenolic compounds and their antioxidant capacities in jujube (Ziziphus jujuba Miller) during three edible maturity stages. LebensmittelWissenschaft + Technologie, 66: 56-62.

Wojdyło, A., Figiel, A., Legua, P., Lech, K., Carbonell-Barrachina, Á. A. and Hernández, F. (2016a). Chemical composition, antioxidant capacity, and sensory quality of dried jujube fruits as affected by cultivar and drying method. Food Chemistry, 207: 170-179.

Wojdyło, A., Carbonellbarrachina, Á. A., Legua, P. and Hernández, F. (2016b). Phenolic composition, ascorbic acid content, and antioxidant capacity of spanish jujube (Ziziphus jujube Mill.) fruits. Food Chemistry, 201: 307-314.

Yahia, Y., Benabderrahim, M. A., Tlili, N., Bagues, M. and Nagaz, K. (2020). Bioactive compounds, antioxidant and antimicrobial activities of extracts from different plant parts of two Ziziphus Mill. species. PloS one, 15(5), e0232599.

Yu, L., Jiang, B. P., Luo, D., Shen, X. C., Guo, S., Duan, J. A. and Tang, Y. P. (2012). Bioactive components in the fruits of Ziziphus jujuba Mill. against the inflammatory irritant action of Euphorbia plants. Phytomedicine, 19(3-4): 239-244

Yuan, C. G., Huo, C., Gui, B., Liu, J. F., \& Chen, Y. S. (2017). Facile phyto-mediated synthesis of silver nanoparticles using Chinese winter jujube (Ziziphus jujuba Mill. cv. Dongzao) extract and their antibacterial/catalytic properties. IET nanobiotechnology, 11(8): 973-980.

Zozio, S., Servent, A., Cazal, G., Mbéguiéambéguié, D., Ravion, S., Pallet, D. and Abel, H. (2014). Changes in antioxidant activity during the ripening of jujube (Ziziphus mauritiana lamk). Food Chemistry, 150(2): 448-456 